\title{
HUBUNGAN ANTARA KEGIATAN OUTINGC LASS DENGAN KEMAMPUAN KOGNITIF MATERI MAKHLUK HIDUP DI SEKOLAH RAMAH ANAK
}

\section{Sriyanti Rahmatunnisa, Fitri Herviana}

Universitas Muhammadiyah Jakarta

Email: sriyanti_rachmatunnisa@yahoo.com, fitriherviana1005@gmail.com

\begin{abstract}
Abstrak:
Penelitian ini dilatar belakangi karena masalah pembelajaran yang terus mengalami perkembangan, oleh karena itu tuntutan untuk mencapai keberhasilan pembelajaran terus ditingkatkan, baik untuk meningkatkan keaktifan, minat, maupun hasil belajar peserta didiik. Upaya yang bisa dilakukan yaitu terletak pada salah satu bentuk wujud dari program sekolah ramah anak, yakni kegiatan outing class (pembelajaran di luar kelas), yang menggunakan keterlibatan lingkungan alam sekitar yang dijadikan sebagai bahan ajar untuk dipelajari. Adapun tujuan dari penelitian ini adalah untuk mengetahui hubungan antara kegiatan outing class dengan kemampuan kognitif materi makhluk hidup. Metode yang digunakan dalam penelitian ini adalah metode kuantitatif dengan desain penelitian korelasional. Hasil penelitian menunjukkan bahwa terdapat hubungan yang signifikan antara kegiatan outing class dengan kemampuan kognitif materi makhluk hidup di kelas III SD Negeri Pengasinan VIII, Kecamatan Rawalumbu, Kota Bekasi. Hal ini terbukti dari hasil perhitungan yang diperoleh pada koefisien korelasi sebesar $\mathrm{r}=$ 0,653 dan koefisien determinasi $R=r^{2}=0,426$, dengan pengujian signifikansi terhadap korelasi diperoleh $t_{\text {hitung }}(8,078)>t_{\text {tabel }}$ $(1,662)$ pada $\alpha=0,05$. Dengan demikian, dapat disimpulkan bahwa terdapat hubungan signifikan antara kegiatan outing class dengan kemampuan kognitif materi makhluk hidup di sekolah ramah anak.
\end{abstract}

Kata Kunci: Outing Class, Kognitif, Makhluk Hidup, Sekolah Ramah Anak.

\section{PENDAHULUAN}

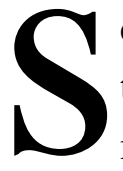
esuai dengan kemajuan zaman, masalah pembelajaran sepertinya terus mengalami perkembangan, oleh karena itu tuntutan untuk mencapai keberhasilan pembelajaran terus ditingkatkan, baik untuk meningkatkan minat, keaktifan belajar, hingga prestasi belajar peserta didik. Di masa sekarang, beberapa sekolah sedang 
mengembangkan dan menggalakkan program sekolah ramah anak yang merupakan paradigma baru terutama di sekolah-sekolah negeri daerah Bekasi, dimana sekolah ramah anak adalah sekolah yang menyuguhi pengalaman belajar dengan proses pembelajaran mengarah pada pengembangan potensi dan karakter peserta didik serta mengondisikan sekolah menjadi nyaman bagi anak, serta menjamin akan memenuhi dan melindungi hak-hak anak. Salah satu domain dari program sekolah ramah anak adalah kegiatan Outing Class (Belajar di luar kelas). Tentu saja jika hal yang tersebut di atas dapat terlaksana, maka dampaknya pun akan menghasilkan kemampuan kognitif yang baik pada peserta didik, terutama pada pembelajaran Ilmu Pengetahuan Alam materi "Makhluk Hidup" yang erat kaitannya dengan kegiatan outing class (pembelajaran di luar kelas), pembelajaran ini mampu membentuk karakter dan sikap ilmiah peserta didik.

Kegiatan outing class lebih memadukan unsur bermain sambil belajar, dimana peserta didik bisa lebih ekspresif dalam mengembangkan ide-ide kreatifnya. Dalam kegiatan ini peserta didik tidak melulu terkungkung belajar di dalam kelas yang terbatas di satu ruangan, tetapi pembelajaran dapat dilakukan di halaman sekolah, di luar area sekolah ataupun di tempat terbuka seperti alam bebas, misalnya: seperti meninjau tempat tertentu atau objek lain, dan itu bukanlah sekadar bermain keluar atau rekreasi, melainkan untuk belajar memperdalam pelajaran dengan melihat kenyataannya. Allah Ta'ala menciptakan alam beserta isinya begitu sempurna dan kaya akan pengetahuan, seperti pantai, kebun, gunung, sawah, danau, hutan dll, bahkan tempat-tempat di lingkungan sekitar juga bisa memberikan pelajaran bermakna bagi peserta didik, misalnya: ladang, peternakan, pasar, puskesmas, bank, kantor-kantor kelurahan dan kecamatan, masyarakat lingkungan sekolah, dll. Peserta didik akan merasa memiliki pengalaman yang berkesan dan bermakna dalam kehidupan nyata mereka terhadap ilmu pengetahuan yang sudah dipelajari, karena kegiatan outing class dapat memberikan pengalaman langsung dan suasana baru bagi peserta didik, dimana hal ini tidak didapatkannya di dalam kelas, sehingga kesempatan tersebut dapat meningkatkan pengetahuan dan pengalaman.

Sedangkan kemampuan kognitif sendiri berkaitan dengan aspek intelektual, meliputi keterampilan berpikir dan pengetahuan. Proses 
berpikir merupakan hal yang harus dikuasai oleh peserta didik agar dapat mengaplikasikan teori kedalam perbuatan sehari-hari.Untuk mengembangkan kemampuan kognitif peserta didik secara optimal, seorang guru harus berinisiatif mendayagunakan lingkungan sekolah sebagai sumber belajar yang konkrit, misalnya memanfaatkan tumbuhan dan keadaan alam di sekitar sekolah, atau pasar, keadaan ekonomi, sosial dan budaya yang berkembang di kehidupan masyarakat, oleh karena itu sangat penting diupayakannya peningkatan pengetahuan guru agar menjadi profesional dan inovatif, terutama dalam pengadaan dan pendayagunaan fasilitas sumber belajar. Tidak hanya pembelajaran kontekstual saja yang dibutuhkan, tetapi juga lingkungan, suasana, dan kondisi belajar yang mendukung, menarik dan menyenangkan peserta didik. Peserta didik bisa bereksplorasi, sambil menikmati alam terbuka, bergembira bersama, dan mencari pengalaman yang mereka butuhkan.

\section{TINJAUAN TEORITIS}

\section{Pengertian Outing Class}

Menurut Rosyid, Rofiqi, dan Yumnah (2019:1-2), pembelajaran di luar kelas (Outing Class) merupakan upaya untuk mengarahkan peserta didik melakukan aktivitas yang dapat membawa mereka mengamati lingkungan sekitar, sesuai materi yang diajarkan, sehingga pendidikan di luar kelas lebih mengarah terhadap pengalaman dan pendidikan lingkungan yang sangat berpengaruh pada kecerdasan peserta didik. Kegiatan outing class atau outdoor activities diyakini mampu memberi wacana baru dalam pembelajaran. Outing class adalah metode dimana guru mengajak peserta didik belajar di luar kelas untuk melihat peristiwa langsung di lapangan dengan tujuan untuk mengakrabkan peserta didik dengan lingkungannya. Outing class dilakukan dengan memanfaatkan lingkungan sekolah sebagai sumber belajar. Peran guru disini adalah sebagai motivator, artinya guru sebagai pemandu agar peserta didik belajar aktif, kreatif, dan akrab dengan lingkungan. Pendidikan di luar kelas (outing class) diartikan sebagai pendidikan yang berlangsung di luar kelas yang melibatkan pengalaman yang membutuhkan partisipasi peserta didik untuk mengikuti tantangan petualangan yang menjadi dasar dan aktivitas luar kelas. 
Outing class disebut sebagai outdoor activities oleh Dadang dan Rizal dalam Widiasworo (2017:80) diartikan sebagai aktivitas luar sekolah yang berisi kegiatan di luar kelas atau sekolah dan di alam bebas lainnya, seperti bermain di lingkungan sekolah, taman, perkampungan pertanian atau nelayan, berkemah, dan kegiatan yang bersifat kepetualangan serta pengembangan aspek pengetahuan yang relevan. Outing class (pendidikan luar kelas) tidak sekadar memindahkan pelajaran ke luar kelas, tetapi dilakukan dengan mengajak peserta didik menyatu dengan alam dan melakukan beberapa aktivitas yang mengarah pada terwujudnya perubahan perilaku peserta didik terhadap lingkungan melalui tahap-tahap penyadaran, pengertian, perhatian, tanggung jawab dan aksi atau tingkah laku. Aktivitas di luar kelas dapat berupa permainan, cerita, olahraga, eksperimen, perlombaan, mengenal kasuskasus lingkungan di sekitarnya dan diskusi penggalian solusi, aksi lingkungan, dan jelajah lingkungan.

\section{Pengertian Kemampuan Kognitif}

Menurut Syah (2005:66) dalam Jauhari (2017:236), Istilah "Cognitive" berasal dari kata cognition yang padanannya knowing, berarti mengetahui. Cognition (kognisi) ialah perolehan, penataan, dan penggunaan pengetahuan. Menurut KBBI, kognisi adalah proses pengenalan dan penafsiran oleh seseorang; kegiatan memperoleh pengetahuan atau usaha mengenali sesuatu melalui pengalaman sendiri. Ranah kejiwaan yang berkedudukan pada otak ini merupakan sumber sekaligus pengendali dari ranah-ranah kejiwaan lainnya, yakni ranah afektif (rasa) dan ranah psikomotor (karsa). Fungsi kognitif bukan hanya menjadi penggerak aktivitas akal pikiran, melainkan juga menjadi menara pengontrol aktivitas perasaan dan perbuatan.

Menurut Sujiono, Zainal, Rosmala, dan Tampiomas (2015:1.7) Kognisi adalah suatu kegiatan atau proses memperoleh pengetahuan (termasuk kesadaran, perasaan, dan sebagainya) atau usaha mengenali sesuatu melalui pengalaman sendiri. Proses kognisi berhubungan dengan tingkat kecerdasan (inteligensi) yang mencirikan seseorang dengan berbagai minat terutama sekali ditujukan kepada ide-ide dan belajar. Kognitif adalah suatu proses berpikir, daya menghubungkan serta kemampuan menilai dan mempertimbangkan. Kognitif lebih bersifat 
pasif atau statis yang merupakan potensi atau daya untuk memahami sesuatu.

\section{Pengertian Pembelajaran IPA Materi Makhluk Hidup}

Menurut Samatowi dalam Aldarmono (2015:62), Ilmu Pengetahuan Alam merupakan terjemahan dari kata Inggris yaitu natural science yang artinya "Ilmu Pengetahuan Alam". Jadi Ilmu Pengetahuan Alam atau sciencenature itu pengertiannya dapat disebut sebagai ilmu tentang alam atau ilmu yang mempelajari peristiwa-peristiwa yang terjadi di alam ini. Kemudian Miarso memberikan definisi Ilmu Pengetahuan Alam pada hakikatnya merupakan pengetahuan yang berakumulasi dan tersusun mengenai alam dan gejalanya. Sedangkan, materi makhluk hidup itu sendiri merupakan salah satu bagian dari pembelajaran Ilmu Pengetahuan Alam (IPA) dimana di dalamnya mempelajari semua tentang asal-usul, karakteristik dan ciri-ciri, serta peran makhluk hidup dalam kelangsungan atau keberadaan alam baik manusia, hewan, maupun tumbuhan.Berdasarkan tinjauan kemampuan kognitif materi makhluk hidup penelitian ini membatasi hubungan outing class khusus dengan ranah kognitif (pengetahuan) berdasarkan Taksonomi Bloom pada mata pelajaran IPA materi makhluk hidup, karena aspek kognitif terlalu luas ranah dan cakupannya sehingga dibatasi hanya berdasarkan tahapan dalam kemampuan kognitif dari yang sederhana sampai yang paling kompleks yaitu pengetahuan, pemahaman, penerapan, analisis, sintesis, dan evaluasi.

\section{Pengertian Sekolah Ramah Anak}

Menurut Kementrian PPPA (2015:14) Konsep Sekolah Ramah Anak adalah program untuk mewujudkan kondisi aman, bersih, sehat, peduli, dan berbudaya lingkungan hidup, yang mampu menjamin pemenuhan hak dan perlindungan anak dari kekerasan, diskriminasi, dan perlakuan salah lainnya, selama anak berada di satuan pendidikan, serta mendukung partisipasi anak terutama dalam perencanaan, kebijakan, pembelajaran dan pengawasan. Sekolah Ramah Anak bukanlah membangun sekolah baru, namun mengkondisikan sebuah sekolah menjadi nyaman bagi anak, serta memastikan sekolah memenuhi hak anak dan melindunginya, karena sekolah menjadi rumah kedua bagi anak, setelah rumahnya sendiri. 
Definisi Sekolah Ramah Anak adalah sebagai berikut: "Satuan pendidikan formal, nonformal, dan informal yang aman, bersih dan sehat, peduli dan berbudaya lingkungan hidup, mampu menjamin, memenuhi, menghargai hak-hak anak dan perlindungan anak dari kekerasan, diskriminasi, dan perlakuan salah lainnya serta mendukung partisipasi anak terutama dalam perencanaan, kebijakan, pembelajaran, pengawasan, dan mekanisme pengaduan terkait pemenuhan hak dan perlindungan anak di pendidikan". Menurut Wuryandani, Fathurrohman, Senen, dan Haryani (2018:87), model Sekolah Ramah Anak (SRA) bukan hanya merupakan konsep abstrak atau metodologi semata. Konsep SRA merupakan prinsip pendidikan yang mengakui bahwa pendidikan yang berpusat pada anak merupakan bagian dari hak asasi manusia. Sekolah Ramah Anak pada prinsipnya merupakan hal penting yang harus diciptakan setiap saat. Konsep SRA diciptakan berdasarkan prinsip demi terealisasi nya hak anak atas pendidikan yang berkualitas.

\section{METODE PENELITIAN}

Metode pada penelitian ini menggunakan metode kuantitatif dengan desain pendekatan korelasional. Teknik pendekatan korelasional digunakan untuk mencari hubungan antara variabel bebas (X) dengan variabel terikat (Y). Hubungan antara variabel bebas dan variabel terikat pada penelitian ini dapat digambarkan dalam bentuk konstelasi hubungan berikut:

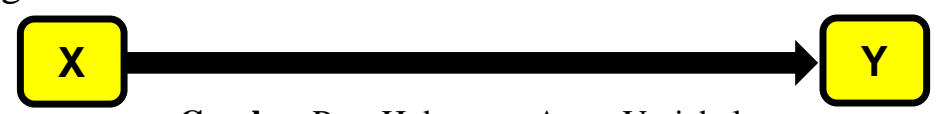

Keterangan:

Gambar Peta Hubungan Antar Variabel

X: Kegiatan Outing Class

Y: Kemampuan Kognitif

Teknik pengumpulan data pada penelitian ini menggunakan teknik non-

tes yakni menggunakan kuesioner (angket).Menurut Muhidin dan Abdurahman (2017:25) Kuesioner adalah salah satu teknik pengumpulan data berbentuk daftar pengajuan pertanyaan atau pernyataan tertulis yang sudah disiapkan sebelumnya untuk diisi oleh responden. Teknik analisis data pada penelitian ini menggunakan statistik deskriptif. Menurut Walpole dalam Riadi (2015:39), statistik deskriptif adalah metode- 
metode tentang pengumpulan dan penyajian suatu gugus data untuk memberikan informasi yang berguna.

Populasi dalam penelitian ini adalah seluruh peserta didik kelas III SD Negeri di Kecamatan Bekasi Timur dan Rawalumbu yang memenuhi karakteristik sekolah ramah anak yang terdiri dari 6 sekolah yakni SDN Pengasinan VIII, SDN. Margahayu XIII, SDN. Bekasi Jaya VI, SDN. Bekasi Jaya VII, SDN. Duren Jaya IV dan SDN. Duren Jaya XIV dengan jumlah populasi sebanyak 451 peserta didik.

Teknik pengambilan sampel pada penelitian ini menggunakan simple random sampling (sampel acak sederhana). Cara pengambilan sampel adalah dengan melakukan undian, yaitu dengan mengundi sekolah ramah anak di 6 SD yang berbeda pada kecamatan Bekasi Timur dan Rawalumbu dengan populasi yang terdiri dari 451 siswa kelas III. Berdasarkan hasil random (undian), terpilihlah sampel di seluruh kelas III SDN PengasinanVIII dengan jumlah 90 siswa yang dijadikan subjek penelitian

\section{HASIL DAN PEMBAHASAN}

Pengolahan data dalam penelitian ini menggunakan teknik analisis Uji Korelasi Product Moment Pearson. Teknik analisis tersebut merupakan statistik parametrik yang mensyaratkan data berasal dari populasi yang berdistribusi normal serta sampel varians homogen dalam penggunaannya. Oleh karena itu, terlebih dahulu dilakukan pengujian prasyarat analisis yaitu pengujian normalitas Kolmogorov-Smirnov dan pengujian homogenitas varians menggunakan Uji Fisher.Hasil dari beberapa pengujian tersebut diantaranya dapat dijelaskan sebagai berikut:

\section{Pengujian Validitas Instrumen}

\section{a. Uji Validitas Variabel X (Kegiatan Outing Class)}

Pengujian validitas instrumen variabel $\mathrm{X}$ dilakukan terhadap 29 orang responden yang dijadikan sebagai uji coba atas 25 pernyataan kuesioner, hasilnya dari 25 pernyataan, sebanyak 21 pernyataan valid dan 4 pernyataan yang drop.

\section{b. Uji Validitas Variabel Y (Kemampuan Kognitif)}

Pengujian validitas instrumen variabel Y dilakukan terhadap 29 orang responden yang dijadikan sebagai uji coba atas 25 pernyataan 
kuesioner, hasilnya dari 25 pernyataan, sebanyak 22 pernyataan valid dan 3 pernyataan yang drop.

\section{Pengujian Reliabilitas Instrumen}

\section{a. Uji Reliabiltas Variabel X (Kegiatan Outing Class)}

Hasil pengujian reliabilitas variabel $X$ didapat $\alpha=0,91>0,60$. Keterangan ini menunjukkan bahwa data variabel $\mathrm{X}$ reliabel, dan soal tersebut bersifat konsisten jika diujikan berulang kali.

\section{b. Uji Reliabilitas Variabel Y (Kemampuan Kognitif)}

Hasil pengujian reliabilitas variabel Y didapat $\alpha_{.}=0,95>0,60$. Keterangan ini menunjukkan bahwa data variabel Y reliabel, dan soal tersebut bersifat konsisten jika diujikan berulang kali.

\section{Pengujian Normalitas}

\section{a. Uji Normalitas Kolmogorov-Smirnov Variabel $\mathbf{X}$}

Hasil pengujian normalitas diperoleh Dhitung $=0,101<$ Dtabel $=0,143$. Keterangan ini menunjukkan bahwa data skor variabel $\mathrm{X}$ berdistribusi normal.

\section{b. Uji Normalitas Kolmogorov-Smirnov Variabel Y}

Hasil pengujian normalitas diperoleh $\mathrm{D}_{\text {hitung }}=0,078<\mathrm{D}_{\text {tabel }}=$ 0,143 . Keterangan ini menunjukkan bahwa data skor variabel $\mathrm{Y}$ berdistribusi normal.

\section{Pengujian Homogenitas Varians}

Analisis korelasi mensyaratkan terpenuhinya asumsi homogenitas varians sampel. Pengujian homogenitas varians berdasarkan skor variabel terikat (Y) yang telah dikelompokkan dengan kesamaan skor variabel bebas (X). Pengujian homogenitas varians dihitung menggunakan Uji Fisher (Uji F). Kriteria pengujian ditentukan berdasar hasil hitung nilai statistik $F_{\text {hitung }}$ yaitu sebagai berikut:

Jika $F_{\text {hitung }}<F_{\text {tabel }}$, artinya persyaratan homogenitas terpenuhi.

Jika $F_{\text {hitung }}>F_{\text {tabel }}$, artinya data tidak homogen.

Ringkasan hasil perhitungan pengujian homogenitas varians seperti disajikan pada tabel berikut:

Tabel Hasil Pengujian Homogenitas Varians

\begin{tabular}{|c|c|c|c|c|}
\hline & $\mathbf{X}$ & $\mathbf{Y}$ & Fhitung & 2,05 \\
\hline $\mathbf{S i}^{\mathbf{2}}$ & 70,18 & 143,57 & Ftabel & 3,96 \\
\hline $\mathbf{n}$ & 90 & 90 & Hasil & HOMOGEN \\
\hline
\end{tabular}


Berdasarkan hasil perhitungan seperti disajikan pada tabel di atas dapat dijelaskan sebagai berikut:

Hasil perhitungan statistik uji homogenitas varians pada skor kemampuan kognitif (Y) atas kegiatan outing class (X) diperoleh

$\mathrm{F}_{\text {hitung }}=2,05<\mathrm{F}_{\text {tabel }}=3,96$ pada $\alpha=0,05$ yang menunjukkan varians $\mathrm{Y}$ atas $\mathrm{X}$ adalah homogen.

Berdasarkan hasil uji homogenitas varians di atas diketahui data penelitian memenuhi persyaratan untuk dianalisis menggunakan statistik teknik Uji Korelasi ProductMomentPearson.

\section{Uji Hipotesis}

Pengujian hipotesis digunakan untuk menguji secara empiris hubungan antara kegiatan outing class (X) dengan kemampuan kognitif (Y) yang diuji menggunakan teknik Uji Korelasi Product Moment Pearson. Hubungan antara kegiatan outingclass dengan kemampuan kognitif dijelaskan dengan menguji hipotesis statistik berikut:

$\mathrm{H}_{0} \quad: \rho=0$, artinya tidak terdapat hubungan antara kegiatan outingclass dengan kemampuan kognitif materi makhluk hidup. Ha: $\rho \neq 0$, artinya terdapat hubungan antara kegiatan outing class dengan kemampuan kognitif materi makhluk hidup. Kekuatan hubungan antara kegiatan outingclass dengan kemampuan kognitif materi makhluk hidup dijelaskan oleh koefisien korelasi yang dihitung menggunakan teknik uji korelasi Product Moment Pearson. Hasil perhitungan koefisien korelasi, koefisien determinasi, dan uji signifikansinya dengan menggunakan Uji Korelasi ProductMomentPearson disajikan dalam tabel 4.4 sebagai berikut:

Tabel Hasil Perhitungan Koefisien Korelasi antara Kegiatan OutingClass (X)

\begin{tabular}{|c|c|c|c|c|}
\hline \multirow{2}{*}{$\mathbf{N}$} & \multicolumn{2}{|c|}{ Koefisien } & \multirow{2}{*}{$\mathbf{T}_{\text {hitung }}$} & \multirow{2}{*}{$\begin{array}{c}\mathrm{T}_{\text {tabel }} \\
\alpha=0,05\end{array}$} \\
\hline & $\mathbf{R}$ & $\mathbf{R}=\mathbf{r}^{2}$ & & \\
\hline 90 & 0,653 & 0,426 & 8,078 & 1,662 \\
\hline
\end{tabular}

$*$ Koefisien korelasi signifikan, $\mathrm{t}_{\text {hitung }}(8,078)>\mathrm{t}_{\text {tabel }}(1,662)$ $\operatorname{pada} \alpha=0,05$.

Berdasarkan hasil perhitungan yang ditunjukkan pada tabel di atas diperoleh koefiesien korelasi sebesar $r=0,653$ dan koefiesien determinasi sebesar $\mathrm{R}=\mathrm{r}^{2}=0,426$. Pengujian signifikansi terhadap korelasi diperoleh $\mathrm{t}_{\text {hitung }}(8,078)>\mathrm{t}_{\text {tabel }}(1,662)$ pada $\alpha=0,05$ menunjukkan bahwa koefisien korelasi signifikan. Jadi, hipotesis 
yang menyatakan terdapat hubungan antara kegiatan outingclass dengan kemampuan kognitif materi makhluk hidup dapat diterima. Artinya, semakin sering kegiatan outingclass akan diikuti oleh tingginya kemampuan kognitif. Sementara itu, koefisien determinasi 0,426 menunjukkan bahwa 43\% variasi kemampuan kognitif dapat dijelaskan oleh variasi kegiatan outing class, sisanya sebanyak $57 \%$ ditentukan oleh faktor lain di luar kegiatan outing class.Dengan demikian, berdasarkan hasil analisis data di atas diperoleh bukti empiris menunjukkan terdapat adanya hubungan yang signifikan antara kegiatan outingclass dengan kemampuan kognitif materi makhluk hidup.

\section{Interpretasi Penelitian}

Pada saat melaksanakan kegiatan belajar mengajar, ada hal-hal penting yang harus diperhatikan guru untuk menarik perhatian peserta didik agar dapat belajar dengan baik, dan membuat peserta didik yang mengalami kesulitan belajar, dapat dengan mudah mengerti dan menganggap bahwa belajar itu menyenangkan. Peserta didik terlihat antusias ketika seorang guru memakai media saat pembelajaran atau mengajaknya belajar sambil bermain di luar kelas mempelajari hal-hal yang ingin diketahui secara langsung, hal ini juga sangat baik dilakukan untuk menghindari kebosanan dan kejenuhan di dalam proses pembelajaran.

Melalui kegiatan outingclass guru dapat mengukur dan mengevaluasi pemahaman peserta didik terhadap apa sudah dipelajari, guru dapat mengetahui bahwa kegiatan outingclass dapat memberikan dampak yang positif bagi kemampuan kognitif peserta didik, bukan hanya mengingat tetapi juga dapat memahami, dan mengaplikasikan pembelajaran dalam kehidupan sehari-hari.

Hal ini terbukti pada penelitian yang telah dilakukan di Sekolah Dasar Negeri Pengasinan VIII, Kecamatan Rawalumbu, Kota Bekasi. Untuk dapat memudahkan peserta didik dalam memahami pelajaran, alangkah baiknya disela-sela kegiatan sekolah diselipkan dengan kegiatan outingclass, tujuannya untuk meningkatkan kemampuan dan membuka wawasan terhadap materi pembelajaran, dan hal ini juga bertujuan supaya peserta didik tidak merasa bosan 
ketimbang hanya melakukan pembelajaran di dalam kelas yang hanya terbatas dengan 4 dinding, sehingga peserta didik dapat mengikuti pembelajaran secara aktif.

\section{SIMPULAN}

Berdasarkan hasil pengujian hipotesis penelitian yang diajukan, terbukti bahwa variabel kegiatan outingclass (X), memiliki hubungan signifikan dengan kemampuan kognitif materi makhluk hidup (Y)Melalui kegiatan outing class, akan membuat peserta didik menaruh perhatian yang tinggi terhadap proses belajar, sehingga peserta didik akan mudah meningkatkan kemampuan kognitif. Hal ini terbukti dari nilai signifikansi $t_{\text {hitung }}=8,078$ lebih besar daripada $t_{\text {tabel }}$ sebesar 1,662 pada taraf kesalahan 5\%, dengan kata lain dapat disimpulkan bahwa semakin sering kegiatan outingclass dilakukan, maka akan semakin tinggi pula hubungannya dengan kemampuan kognitif.

\section{DAFTAR PUSTAKA}

Al Darmono. (2015). Pendekatan Edutainment Dalam Pembelajaran IPA SD. Jurnal Al-Mabsut Volume 9(2): 61-75. p-ISSN: 2089-3426; e-ISSN: 2502-213X Publisher: LP3M Sekolah Tinggi Agama Islam Ngawi http://e-resources.perpusnas.go.id

Çobanoğlu, Fatma dkk. (2018). Child-friendly Schools: An Assessment of Secondary Schools. Universal Journal of Educational Research Vol 6(3): 466-477. http://www.hrpub.org DOI: 10.13189/ujer.2018.060313 http://e-resources.perpusnas.go.id

Hildayatni, Dita; Triwoelandari, Retno dan Hakiem, Hilman. (2019). Pengaruh Penggunaan Modul Pembelajaran IPA Terintegrasi Nilai Agama Terhadap Peningkatan Karakter Rasa Ingin Tahu Siswa. MUALLIMUNA: Jurnal Madrasah Ibtidaiyah Vol 5(1), Oktober 2019 (1-10). e-ISSN: 2476-9703 Terbit sejak 2015, http://ojs.uniska-bjm.ac.id/index.php/jurnalmuallimuna

Heryanto, Wawan Prasetyo; Fata, Samsul dan Yakino. (2019). Analisis Karakter Siswa dan Kemampuan Guru IPA Dalam Menerapkan Pembelajaran Berbasis Al-Qur'an. JPS: Jurnal Pendidikan Sains Vol 7(1): 64-69. e-ISSN: 2502-1443; p-ISSN: 2339-0786, http://jurnal.unimus.ac.id/index.php/JPKIMIA. 
Ibda, Fatimah. (2015). Perkembangan Kognitif; Teori Jean Piaget. INTELEKTUALITA Vol 3(1): 27-38. explore.openaire.eu http://e-resources.perpusnas.go.id

Jauhari, Moh Irmawan. (2017). Taksonomi Bloom dan Implementasi Kurikulum Berbasis Multikultural. JALIE: Journal of Applied Linguistics and Islamic Education Vol 1(1), September 2017 (234-253). p-ISSN: 2549-7804; e-ISSN: 2549-8622. http://ejournal.inkafa.ac.id

Khiyarusoleh, Ujang. (2016). Konsep Dasar Perkembangan Kognitif Pada Anak Menurut Jean Piaget. Jurnal Dialektika Jurusan PGSD Vol 5(1), Maret 2016 (1-10). ISSN: 2089- 3876. https://journal.peradaban.ac.id

Kementrian Pemberdayaan Perempuan dan Perlindungan Anak (KPPA). Panduan Sekolah Ramah Anak. November 2015. Deputi Tumbuh Kembang Anak Kementrian Pemberdayaan Perempuan dan Perlindungan Anak. Jakarta.

Latifa, Umi. (2017). Aspek Perkembangan pada Anak Sekolah Dasar; Masalah dan Perkembangannya. Academica: Journal of Multidiciplinary Studies Vol 1(2), Juli-Desember 2017 (185196). ISSN: 2579-9703 (P) | ISSN: 2579-9711 (E). https://ejournal.iainsurakarta.ac.id

Muhidin, Sambas Ali dan Abdurahman, Maman. (2017). Analisis Korelasi, Regresi, dan Jalur dalam Penelitian; (Dilengkapi Aplikasi Program SPSS). Bandung: CV. Pustaka Setia.

Mundilarto, dan Pamulasari, Haorensa Enggar. (2017). Outdoor Learning Model through Fieldwork to Improve Physics Achievement in Dynamic Fluid. Journal of TURKISH SCIENCE EDUCATION Vol 14(3), September 2017 (73-86). ISSN:13046020. http://www.tused.org

Nuraeni, Lenny; Andrisyah dan Nurunnisa, Rita. (2020). Efektivitas Program Sekolah Ramah Anak dalam Meningkatkan Karakter Anak Usia Dini. Jurnal Obsesi: Jurnal Pendidikan Anak Usia Dini Vol 4(1): 20-29. ISSN: 2549-8959 (Online) 2356-1327 (Print). DOI: $10.31004 /$ obsesi.v4i1.204

Riadi, Edi. (2015). Metode Statistika Parametrik \& Non-parametrik Untuk Penelitian Ilmu-ilmu Sosial dan Pendidikan. Tanggerang: Pustaka Mandiri. 
Rosyid, Moh Zaiful, dkk. (2019). Outdoor Learning (Belajar di Luar Kelas). Malang: Literasi Nusantara.

Setiawan, Ika Tony dan Koesdyantho, AR. (2018). Pengaruh Metode Outing Class Terhadap Minat Belajar Pada Siswa Kelas IV SDN Sambirejo No. 148 Surakarta Tahun Pelajaran 2017/2018. eISSN: 2621-7414; p-ISSN: 1907-5928 DOI : 10.33061 https://jurnal-mahasiswa.unisri.ac.id diakses 3 Januari 2020.

Setiyorini, Nunung Dwi. (2018). Pembelajaran Kontekstual IPA Melalui Outdoor Learning di SD Alam Ar-Ridho Semarang. Al-Mudaris: Journal of Education Vol 1(1) 30-38. p-ISSN: 2620-5831; eISSN: 2620-4355 https://e-journal.staima-alhikam.ac.id/index.php/almudarris/ diakses 3 Januari 2020.

Sugiyono. (2017). Statistika Untuk Penelitian. Bandung: Alfabeta. (2018). Metode Penelitian Kuantitatif. Bandung: Alfabeta.

Sujiono, Yuliani Nurani dkk. (2015). Modul 1; Metode Pengembangan Kognitif. Universitas Terbuka 1 (372.21): 1-35. https://www.pustaka.ut.ac.id

Torkos, Henrietta. (2018). Risk Management in Outdoor Learning Experiences. Journal Plus Education Vol 19(1): 185-198. ISSN: 1842-077X, E-ISSN (online) 2068-1151. https://www.uav.ro

Utami, Ratnasari Diah dkk. (2017). Implementasi Penerapan Sekolah Ramah Anak Pada Penyelenggaraan Pendidikan Sekolah Dasar. The 5th Urecol Proceeding, PGSD FKIP Universitas Muhammadiyah Surakarta, Yogyakarta, 18 Februari 170-176, 2017. ISBN 978-979-3812-4. https://ums.ac.id

Utari, Retno. (2015). Taksonomi Bloom; Apa dan Bagaimana Menggunakannya?. Widyaiswara Madya, Pusdiklat KNPK. https://www.academia.edu

Widiasworo, Erwin. (2017). Strategi \& Metode Mengajar Siswa di Luar Kelas (Outdoor Learning); Secara Aktif, Kreatif, Inspiratif, dan Komunikatif. Yogyakarta: Ar-ruzz Media.

Wuryandani, Wuri dkk. (2018). Implementasi Pemenuhan Hak Anak Melalui Sekolah Ramah Anak. Jurnal Civics: Media Kajian Kewarganegaraan Vol 15(1): 86-94. p-ISSN: 1829-5789; e-ISSN: 2541-1918. https://journal.uny.ac.id/index.php/civics/index

Yulianto, Agus. (2016). Pendidikan Ramah Anak: Studi Kasus SDIT Nur Hidayah Surakarta. Jurnal At-Tanbawi Vol 1(2), JuliDesember (137-156). ISSN: 2527-8231 (P); 2527-8177 (E). DOI 10.22515/attarbawi.v1i2.192 https://ejournal.iainsurakarta.ac.id 
Zahroh, Lailatul. (2017). Pembelajaran Luar Kelas, Aplikasi Pembelajaran AKIK. Halaqa: Islamic Education Journal Vol 1(2): 87-96. ISSN $2503-5045$ (online). DOI http://doi.org/10.21070/halaqa.v1i2.1244http://ojs.umsida.ac.id/index.p hp/halaqa 